\title{
Nanoscale
}

Check for updates

Cite this: Nanoscale, 2020, 12, 17405

\section{Tailoring molecular interactions between microporous polymers in high performance mixed matrix membranes for gas separations $\uparrow$}

\author{
Cher Hon Lau, (D) *a Kristina Konstas, ${ }^{\mathrm{b}}$ Cara M. Doherty, (D) ${ }^{\mathrm{b}}$ Stefan J. D. Smith, (D) ${ }^{\mathrm{b}}$ \\ Rujing Hou, (D) b,c Huanting Wang, (D) ${ }^{c}$ Mariolino Carta, (D) ${ }^{\mathrm{d}}$ Heewook Yoon, ${ }^{\mathrm{e}}$ \\ Jaesung Park, ${ }^{e}$ Benny D. Freeman, ${ }^{e}$ Richard Malpass-Evans, ${ }^{f}$ Elsa Lasseuguette, (D) a \\ Maria-Chiara Ferrari, ${ }^{a}$ Neil B. McKeown (D) ${ }^{f}$ and Matthew R. Hill (DD $* b, c$
}

\begin{abstract}
Membranes are crucial to lowering the huge energy costs of chemical separations. Whilst some promising polymers demonstrate excellent transport properties, problems of plasticisation and physical aging due to mobile polymer chains, amongst others, prevent their exploitation in membranes for industrial separations. Here we reveal that molecular interactions between a polymer of intrinsic microporosity (PIM) matrix and a porous aromatic framework additive (PAF-1) can simultaneously address plasticisation and physical aging whilst also increasing gas transport selectivity. Extensive spectroscopic characterisation and control experiments involving two near-identical PIMs, one with methyl groups (PIM-EA(Me $\left.\left.\mathrm{M}_{2}\right)-\mathrm{TB}\right)$ and one without (PIM-EA( $\left.\left.\mathrm{H}_{2}\right)-\mathrm{TB}\right)$, directly confirm the key molecular interaction as the adsoprtion of methyl groups from the PIM matrix into the nanopores of the PAF. This interaction reduced physical aging by $50 \%$, suppressed polymer chain mobilities at high pressure and increased $\mathrm{H}_{2}$ selectivity over larger gases such as $\mathrm{CH}_{4}$ and $\mathrm{N}_{2}$
\end{abstract}

Received 25th June 2020 Accepted 6th August 2020 DOI: $10.1039 / \mathrm{d} 0 \mathrm{nr} 04801 \mathrm{a}$ rsc.li/nanoscale deployed for gas ${ }^{4}$ and liquid ${ }^{5}$ separations for over 40 years, while hundreds of new polymers with superior transport behavior have been reported.

Despite advances in polymer science, challenges beyond their inherent transport behavior have limited the implementation of new polymers into commercial modules. For example, regardless of film thickness, polymers with intrinsic microporosity (PIMs) are susceptible to $\mathrm{CO}_{2}$-induced plasticisation and physical aging ${ }^{6-8}$ and possess insufficient gas selectivity. Plasticisation arises from sorbed molecules mobilising polymer chains, reducing gas selectivities. ${ }^{9}$ Due to dual mode sorption, it can also cause gas permeability to reduce before increasing at higher pressures. ${ }^{10}$ Meanwhile, physical aging occurs naturally as polymer chains converge, reducing gas permeabilities. $^{11}$

A strategy to reduce these effects is to rigidify polymer chains. This has been achieved with mixed matrix membranes (MMMs) comprising microporous additives such as metal organic frameworks, ${ }^{12}$ porous aromatic frameworks (PAFs), ${ }^{13}$ covalent organic frameworks, ${ }^{14}$ metal organic polyhedra, ${ }^{15}$ and hypercrosslinked polymers (HCPs). ${ }^{16,17}$ Amongst these additives, PAFs can best control physical aging of PIMs where PIM/ PAF composites only lose $20 \%$ of their $\mathrm{CO}_{2}$ permeabilities. ${ }^{18}$ Meanwhile PIM composites comprising other microporous additives (MOFs, ${ }^{19} \mathrm{HCPs}^{17}$ fumed silica ${ }^{19}$ ) lose up to $80 \%$ of 


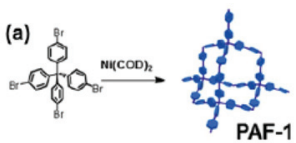

(b)

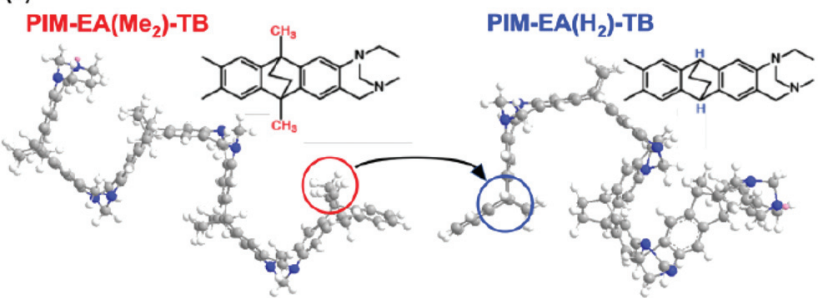

Fig. 1 (a) Chemical structure of PAF-1, a highly microporous polymer first reported in 2009. ${ }^{21}$ (b) The methyl groups in PIM-EA(Me $\left(\mathrm{e}_{2}\right)-\mathrm{TB}^{22}$ are absent in the new polymer, PIM-EA( $\left.\mathrm{H}_{2}\right)-\mathrm{TB}$, which results in reduction of inter-chain distances ( $d$-space), alteration of preferred interaction sites on PIM chains with PAF-1, and impacting chain mobility during physical aging and plasticisation.

their $\mathrm{CO}_{2}$ permeabilities. To date, it has been demonstrated that such approaches can only address a single limitation of polymer membrane. ${ }^{13,15,16,19,20}$ Moreover, this approach may reduce gas selectivities when incompatible additives are used.

Here we show that plasticisation, physical aging and poor gas selectivity of polymer membranes can be simultaneously addressed in a single MMM by tailoring interactions between additives and specific sites of the polymer matrix. The polymer matrices deployed in this work were PIMs that contained Tröger base (TB) and ethanoanthracene (EA), with (PIM-EA $\left.\left(\mathrm{Me}_{2}\right)-\mathrm{TB}\right)^{22}$ and without (PIM-EA( $\left.\left.\mathrm{H}_{2}\right)-\mathrm{TB}\right)^{23}$ methyl pendent groups at its two bridgehead positions (Fig. 1). Due to the better capability to control physical aging of PIMs, ${ }^{18}$ PAF-1, a microporous network polymer comprised of tetrahedral carbon atoms linked by biphenyl groups with 2 pore sizes centred at 0.2 and $1.3 \mathrm{~nm}$ (ref. 13 and 21) was deployed as an additive. The average diameter of PAF-1 nanoparticles deployed here in this work were $200 \mathrm{~nm}$ (Fig. S1-4†). The nonmethylated PIM-EA( $\left.\mathrm{H}_{2}\right)$-TB served as a control to demonstrate the impact of a trivial chemical structural difference in the polymer matrix on additive interactions and compatibility. This led to contrasting PIM chain mobility, aging mechanisms and gas transport behaviour at various operating conditions.

\section{Results and discussion}

Impact of methyl groups on interactions with PAF-1 and physical aging

$T_{1}$ relaxation times of carbon atoms in polytrimethylsilylpropyne ${ }^{24}$ and PIM- $1^{25}$ obtained from solid state ${ }^{13} \mathrm{C}$ NMR could be used to describe polymer chain mobility, where relative decreases in $T_{1}$ relaxation times (w.r.t those of as-cast polymers) infer a greater mobility of carbon atoms, while increments in $T_{1}$ relaxation times indicate less mobile carbon atoms. Hence, the mobility of carbon atoms in functional groups located on the bulky side chains or flexible points on these polymer chains are excellent indicators of plasticisation and physical aging. ${ }^{25}$ Based on these observations, here we hypothesise that the key drivers of physical aging in PIMs studied here were; namely, ethylene bridges, TB methylene bridge, methyl group (PIM-EA(Me $\mathrm{Me}_{2}$-TB only) and the methine group (PIM-EA( $\left.\mathrm{H}_{2}\right)$-TB only). This hypothesis was validated here with solid state ${ }^{13} \mathrm{C}$ NMR.

The carbon atoms in methyl groups, ethylene bridge, and TB methylene bridge of PIM-EA( $\left(\mathrm{Me}_{2}\right)$-TB became more mobile as the polymer chains converged during physical aging (Fig. 2). The degree of freedom in these functional groups was as follows: methyl (C9) > TB methylene bridge (C1) > ethylene bridge (C7, C8); indicating that PIM-EA( $\left(\mathrm{Me}_{2}\right)$-TB chain convergence was primarily driven by the EA methyl groups. PAF- 1 preferred to interact with methylated bulky side-chains of polyacetylenes ${ }^{26}$ and PIM-1. ${ }^{18}$ However, here, we observed that PAF-1 only appeared to immobilize the EA ethylene and TB methylene bridges in PIM-EA( $\left(\mathrm{Me}_{2}\right)$-TB, but not the EA methyl groups. This was because the presence of other $\mathrm{CH}$-based functional groups altered the preferred interaction sites between PAF-1
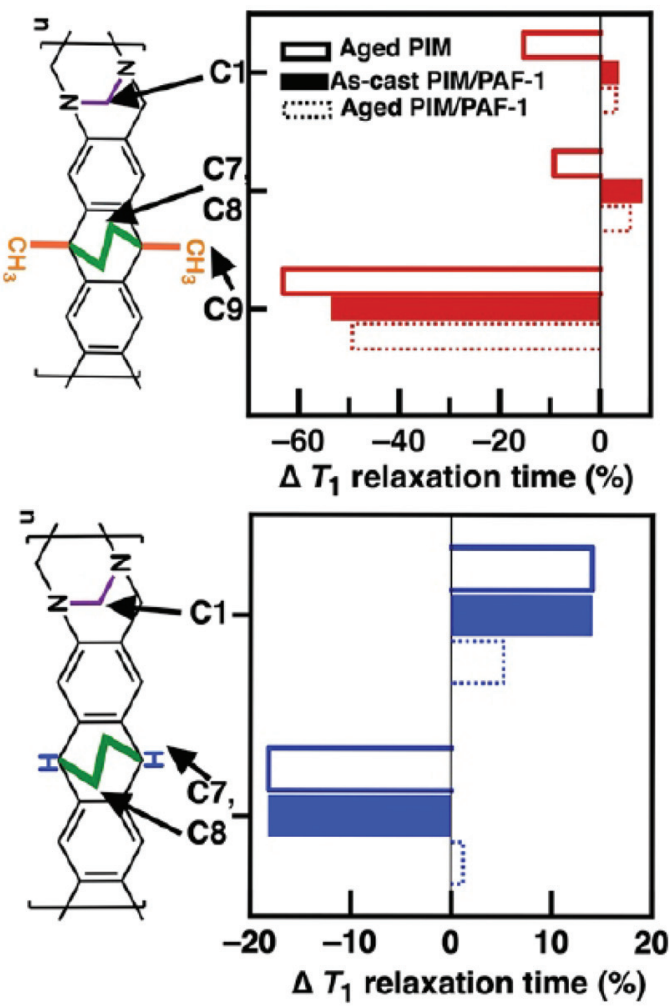

Increase in $\Delta T_{1}$ relaxation time = Mobility $\downarrow$ Decrease in $\Delta T_{1}$ relaxation time $=$ Mobility $\uparrow$

Fig. $2 T_{1}$ relaxation times of carbon atoms obtained from ${ }^{13} \mathrm{C}$ solid state NMR spectroscopy correlate to molecular mobility. Relative $T_{1}$ decrease (w.r.t. as-cast polymer - black line at $0 \%$ ) correlates to more mobile atoms, and vice versa. ${ }^{24}$ PAF-1 rigidifies the EA ethylene and TB methylene bridges in PIM-EA(Me $\left.\mathrm{Me}_{2}\right) \mathrm{TB}$, while having minimal impact on these bridges in PIM-EA( $\left.\mathrm{H}_{2}\right)-\mathrm{TB}$. T1 values of main chain carbon atoms are shown in Fig. S19, ESI.† 
and the polymer matrix. Facing competition from both ethylene and methylene bridges where PAF-1 preferred to interact with and rigidify the EA ethylene bridge, interactions between EA methyl groups and PAF-1 were minimized.

The immobilization of both EA ethylene and TB methylene bridges was achieved through non-bonding physical interactions for example, weak aliphatic-aromatic $\mathrm{CH} / \pi$ interactions, as the NMR spectra of both the neat polymer and nanocomposite film contained similar peak positions (Fig. S20†).

Such interactions were most likely to happen between the ethylene and methylene bridges and the aromatic rings of PAF-1, similar to the stabilization of biomolecules ${ }^{27,28}$ and organic crystals $^{29}$ via London dispersion forces governing $\mathrm{CH} /$ $\pi$ interactions between aromatic and aliphatic structures. ${ }^{30}$ The absence of pendant methyl groups in PIM-EA( $\left(\mathrm{H}_{2}\right)-\mathrm{TB}$ changed the way these polymer chains aggregated and interacted with PAF-1. As PIM-EA( $\left(\mathrm{H}_{2}\right)$-TB aged, both the ethylene bridge and methine group on the $\mathrm{EA}\left(\mathrm{H}_{2}\right)$ unit became more mobile, while the TB methylene bridge lost mobility.

Clearly, PIM-EA( $\left.\mathrm{H}_{2}\right)$-TB chain convergence during aging was driven primarily by the $\mathrm{EA}\left(\mathrm{H}_{2}\right)$ unit; leading to smaller and less free volume (Tables $\mathrm{S} 2$ and $3 \dagger$ ) that restricted the mobility of TB methylene bridges. Meanwhile, although PAF-1 preferred to interact with both the methine group and ethylene bridges of PIM-EA( $\left(\mathrm{H}_{2}\right)$-TB, the mobility of these functional groups was retained. Conversely, the mobility of TB methylene bridges in PIM-EA( $\left.\mathrm{H}_{2}\right)$-TB/PAF-1 nanocomposites was enhanced, most likely due to minimal interactions between this functional group and PAF-1. The negligible influence of PAF-1 on the mobility of a $\mathrm{CH}$-based functional group, possibly due to the inability of PAF-1 to break up the inter-PIM chain interactions in PIM-EA( $\left.\mathrm{H}_{2}\right)$-TB. This was validated here by characterising the behaviour of PIMs studied here and their interactions with PAF-1 in solution phase. The viscosity of solutions containing 2 wt $\%$ PIM-EA( $\left.\mathrm{H}_{2}\right)$-TB in chloroform was $100 \%$ higher than that of PIM-EA( $\left(\mathrm{Me}_{2}\right)$-TB (Fig. 3). This observed effect is not an artefact of polymer molecular weight where high molecular weight PIM typically increase the viscosity of solutions. ${ }^{31}$ The

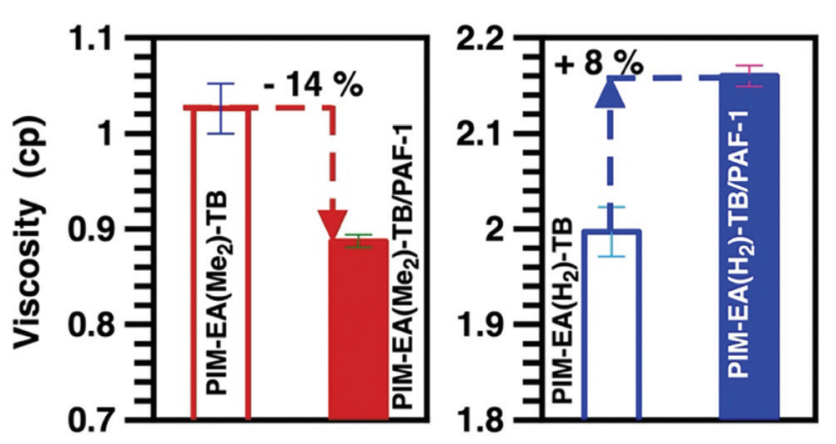

Fig. 3 Viscosity measurements of solutions containing 2 wt\% PIM-EA $\left(\mathrm{Me}_{2}\right)$-TB $(\square)$, PIM-EA(Me $\left.\mathrm{M}_{2}\right)$-TB/PAF-1 $\square$ ), PIM-EA $\left(\mathrm{H}_{2}\right)$-TB ( $\square$ ), and PIM-EA $\left(\mathrm{H}_{2}\right)-\mathrm{TB} / \mathrm{PAF}-1(\square)$. The concentration of PAF-1 in these solutions is 10 wt\% w.r.t. to PIM weight. molecular weight of PIM-EA(Me $\left.\mathrm{Me}_{2}\right)$-TB was $155800 \sim 3$ times larger than that of PIM-EA( $\left.\mathrm{H}_{2}\right)$-TB.

Here the lack of methyl groups promoted inter-chain interactions; ${ }^{32}$ leading to greater PIM-EA(H2)-TB chain agglomeration. In contrast, for PIM-EA(Me2)-TB, the pendant methyl groups reduced polymer chain interactions thus lowering viscosity. The viscosity of solution mixtures provides insight into the nature of polymer-PAF interactions. ${ }^{18}$ Typical of systems with non-compatible components, 10 wt\% PAF-1 (w.r.t. polymer concentration) increased the solution viscosity of PIM-EA( $\left(\mathrm{H}_{2}\right)$-TB by $8 \%$. In contrast, PAF-1 reduced the viscosity of PIM-EA( $\left(\mathrm{Me}_{2}\right)$-TB solutions. This could be ascribed to better interactions between the PAF additive and the PIM chains, possibly due to adsorption of polymer chains on the additive, the threading of polymer chains into additive pores and enhanced porosity within the mixture. ${ }^{18,33}$ The degree of interaction between PAF-1 and PIMs also impacted on the physicochemical structure of resultant films.

From SAXS/WAXS spectra of neat PIM films, the inter-chain distance between PIM chains was smaller by $30 \%$ for PIM-EA $\left(\mathrm{H}_{2}\right)$-TB $(d$-space $=7.7 \AA$, Fig. $4 \mathrm{a})$ relative to PIM-EA( $\left(\mathrm{Me}_{2}\right)$-TB $(d$-space $=11 \AA$, Fig. $4 \mathrm{~b})$. Typical of non-compatible systems, ${ }^{34}$ PAF- 1 enhanced $d$-spacing in PIM-EA( $\left.\mathrm{H}_{2}\right)$-TB by $200 \%$ (from $7.7 \AA$ to $23.6 \AA$ ) (Fig. 4c). This $d$-space was reduced by $40 \%$ to $14.8 \AA$ upon aging. Meanwhile, for the PIM-EA(Me $\left.\mathrm{M}_{2}\right)-\mathrm{TB} / \mathrm{PAF}-1$ composite, the polymer chains were only propped further apart by $60 \%$ (Fig. $4 \mathrm{~d}$ ) relative to the neat film and the largest pore size distributions in PIM-EA(Me $\mathrm{Me}_{2}$-TB/PAF-1 were only reduced by $4 \%$ after aging. It appeared that PAF- 1 caused PIM-EA( $\left.\mathrm{H}_{2}\right)$-TB to age faster while reducing the physical aging rate of PIM-EA( $\left.\mathrm{Me}_{2}\right)$-TB. This was also validated with single gas permeation results collected from samples aged naturally (stored in ambient conditions) over 730 days (Fig. S22, ESI $\dagger$ ). This significant structural change was reflected in data from positron annihilation lifetime spectroscopy (PALS) (Tables S2 and 3, ESI $\dagger$ ). Although the PALS average pore sizes remained
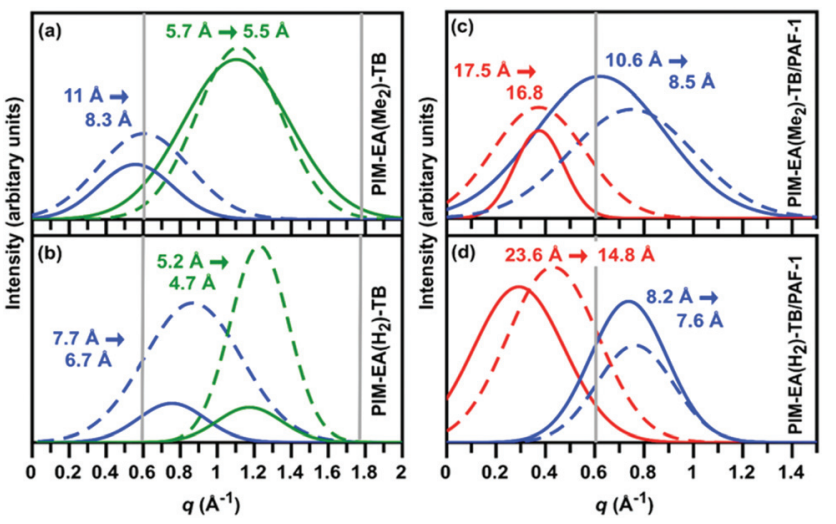

Fig. 4 SAXS/WAXS raw data was fitted with a sum of Gaussian plots using MagicPlot to obtain various pore size distributions (as-cast samples - solid lines, aged samples (90 days) - dashed lines): (a) neat film of PIM-EA(Me 2$)-T B$; (b) neat film of PIM-EA( $\left.\mathrm{H}_{2}\right)-T B$; (c) film of PIM-EA(Me $\left.\mathrm{M}_{2}\right)-\mathrm{TB} / \mathrm{PAF}-1$ and (d) film of PIM-EA( $\left.\mathrm{H}_{2}\right)-\mathrm{TB} / \mathrm{PAF}-1$. 
relatively stable from aging, there was an overall drop in fractional free volume as the number of large free volume elements decreased while increasing the number of smaller free volume elements. Without PAF-1, there was an overall decrease in size and number of free volume elements with aging. To untangle the effects of physical aging rates due to film thicknesses, we measured the gas permeability loss rates of $15 \mu \mathrm{m}$ thin and $139 \mu \mathrm{m}$ thick PIM-EA(Me $\mathrm{Me}_{2}$-TB/PAF 1 films (Fig S22, ESI $\dagger$ ). The loss in $\mathrm{H}_{2}$ permeabilities across these films of different thicknesses is identical (10-20\%), indicating that physical aging occurs at the same rate in PIM-EA( $\left(\mathrm{Me}_{2}\right)-\mathrm{TB} /$ PAF-1, regardless of film thickness.

\section{Impact of methyl groups on interactions with PAF-1 and plasticisation}

Gas-induced plasticisation (gas pressure increase, gas permeability increase) and dual mode sorption (gas pressure increase, gas permeability decrease) in polymers are best illustrated with a highly sorbing molecule like $\mathrm{CO}_{2}{ }^{8,35}$ Here, we used both pure and mixed (50:50, stage cut $0.1 \%) \mathrm{CO}_{2}$ and $\mathrm{CH}_{4}$ gases over pressures or partial pressures of 2 to $20 \mathrm{~atm}$ (Fig. 5). Typical of dual mode sorption ${ }^{36}$ and widely observed in polymer membranes that were not plasticised significantly by the permeating gas, ${ }^{37}$ the $\mathrm{CO}_{2}$ permeabilities of PIM-EA $\left(\mathrm{Me}_{2}\right)$-TB/PAF-1 and PIM-EA( $\left.\mathrm{H}_{2}\right)$-TB/PAF-1 were reduced by $2 \%$ and $20 \%$, respectively (Fig. $5 \mathrm{a}$ and b) as single gas $\mathrm{CO}_{2}$ pressure increased from 2 to 20 bar. Likewise, the mixed gas $\mathrm{CO}_{2}$ permeabilities of both PIM-EA(Me $\left.{ }_{2}\right)$-TB/PAF-1 and PIM-EA $\left(\mathrm{H}_{2}\right)$-TB/PAF-1 were also reduced by similar amounts at higher $\mathrm{CO}_{2}$ partial pressures. The moderation in $\mathrm{CO}_{2}$-induced swelling for PIM-EA( $\left(\mathrm{Me}_{2}\right)$-TB was consistent with the greater interaction of this polymer host with the PAF-1 additive where rigidified PIM EA( $\left(\mathrm{Me}_{2}\right)-\mathrm{TB}$ chains were less likely to swell. Meanwhile, higher $\mathrm{CH}_{4}$ pressures did not result in any significant changes in single gas $\mathrm{CH}_{4}$ permeabilities (Table S9, ESI $†$ ). The main difference here was in the 63 and 39\% increase in mixed gas $\mathrm{CH}_{4}$ permeabilites of PIM-EA( $\left(\mathrm{Me}_{2}\right)-\mathrm{TB} / \mathrm{PAF}-1$ and PIM-EA( $\left.\mathrm{H}_{2}\right)$-TB/PAF-1, respectively. The enhancements in mixed gas $\mathrm{CH}_{4}$ permeabilities underpinned an unexpected loss in mixed gas $\mathrm{CO}_{2} / \mathrm{CH}_{4}$ selectivities, possibly due to a combination of dual mode sorption effect reducing mixed gas $\mathrm{CO}_{2}$ permeability and moderated swelling of the PIM matrices at high $\mathrm{CO}_{2}$ pressures that enhanced the permeation of larger gases such as $\mathrm{CH}_{4}$ (Fig. 5c-e). Similar to physical aging, where permeation of small gas molecules in PIM-EA( $\left(\mathrm{Me}_{2}\right)-\mathrm{TB} / \mathrm{PAF}-1$ nanocomposites were less affected (Fig. S23, ESI $\dagger$ ), the impact of $\mathrm{CO}_{2}$ induced swelling and plasticisation favoured the mixed gas permeation of smaller gases $\left(\mathrm{CO}_{2}\right.$ kinetic diameter $\left.3.3 \AA\right)$ over larger gases $\left(\mathrm{CH}_{4}\right.$ kinetic diameter $\left.3.8 \AA\right)$ as a function of pressure.

\section{Impact of methyl groups on interactions with PAF-1 on gas separations}

$10 \mathrm{wt} \%$ PAF-1 enhanced all gas permeabilities of PIM-EA($\left(\mathrm{H}_{2}\right)-$ ТВ by at least $110 \%$, but majorly reduced gas selectivities (Fig. S21†). This was typical of nanocomposites containing
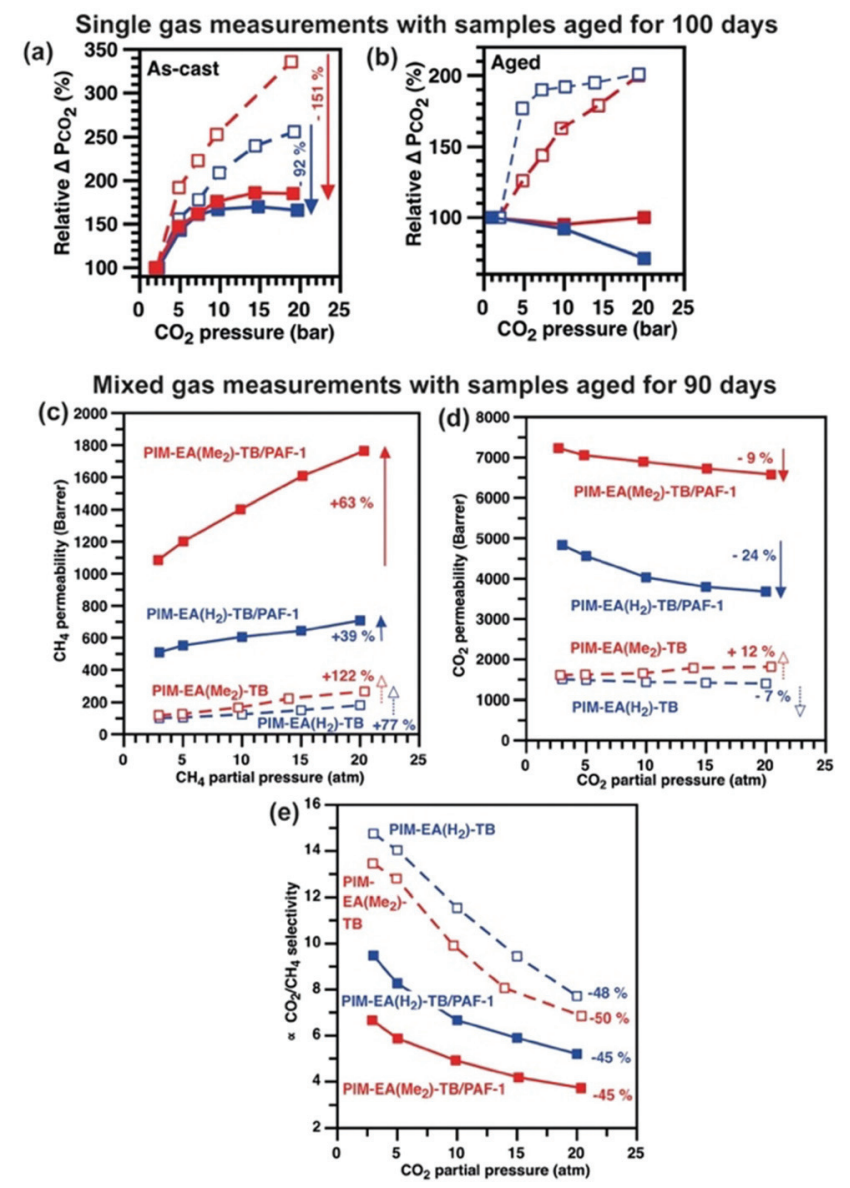

Fig. 5 The effects of increasing $\mathrm{CO}_{2}$ pressure on $\mathrm{CO}_{2}$ permeabilities of (a) as-cast and (b) aged (100 days) PIM-EA(Me $\mathrm{Me}_{2}$-TB ( $\square$ ), PIM-EA(Me $\left.\mathrm{M}_{2}\right)$-TB/ PAF-1 $\left(\square\right.$ ), PIM-EA( $\left.\mathrm{H}_{2}\right)-\mathrm{TB}(\square)$, and PIM-EA $\left(\mathrm{H}_{2}\right)-\mathrm{TB} / \mathrm{PAF}-1(\square)$ membranes are investigated here with $\mathrm{CO}_{2}$. The effects of $\mathrm{CO}_{2}$ plasticization on mixed (c) $\mathrm{CH}_{4}$, (d) $\mathrm{CO}_{2}$ gas permeabilities and (e) $\mathrm{CO}_{2} / \mathrm{CH}_{4}$ mixed gas selectivity were characterized using samples that have aged for 90 days, and over a range of $\mathrm{CO}_{2}$ partial pressures at $35{ }^{\circ} \mathrm{C}$ with gas mixtures containing $50: 50 \mathrm{~mol} \%$ of $\mathrm{CO}_{2}: \mathrm{CH}_{4}$ and a stage cut $<0.1$. Mixed gas data for plasticization were collected from the Freeman labs at UT, Austin. Lines were drawn to guide the eye, and permeability values are $\pm 5 \%$ within standard deviation.

components with low compatibility, ${ }^{38}$ where the bulk polymer phase was not in intimate contact with the dispersed phase. ${ }^{39}$ As PAF-1 increased the $d$-space in PIM-EA( $\left(\mathrm{H}_{2}\right)$-TB by $200 \%$, the Knudsen diffusion of $\mathrm{H}_{2}, \mathrm{~N}_{2}$, and $\mathrm{CH}_{4}$ were facilitated; leading to drastic gas permeability enhancements. Rapid physical aging of the PIM-EA( $\left.\mathrm{H}_{2}\right)$-TB/PAF-1 nanocomposites was apparent, consistent with the reduction in $d$-spacing indicated by SAXS/WAXS.

In contrast, the strong interaction between PAF-1 and PIM-EA(Me $\left.\mathrm{Me}_{2}\right)$ TB delivered a remarkable increase in both permeability and selectivity, surpassing the 2015 upper bounds for light gas separations including $\mathrm{H}_{2} / \mathrm{N}_{2}, \mathrm{H}_{2} / \mathrm{CH}_{4}$, and $\mathrm{O}_{2} / \mathrm{N}_{2}$ reported by Pinnau et al. ${ }^{44}$ (Fig. 6a-c). $10 \mathrm{wt} \%$ PAF-1 enhanced the $\mathrm{H}_{2}$ permeability of PIM-EA($\left(\mathrm{Me}_{2}\right)$-TB by $71 \%$ while reducing $\mathrm{N}_{2}$ and $\mathrm{CH}_{4}$ permeabilities by 5 and $11 \%$, respectively 

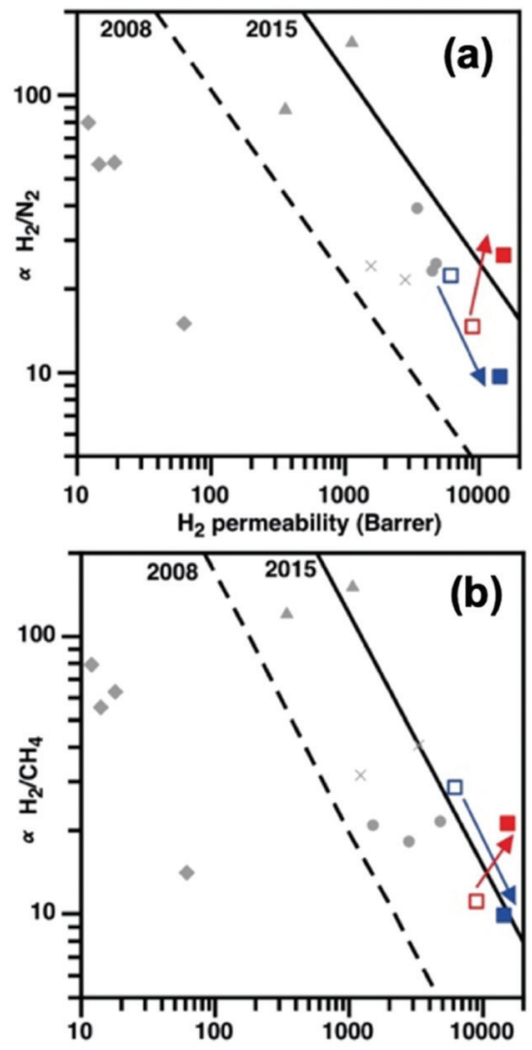

$\mathrm{H}_{2}$ permeability (Barrer)

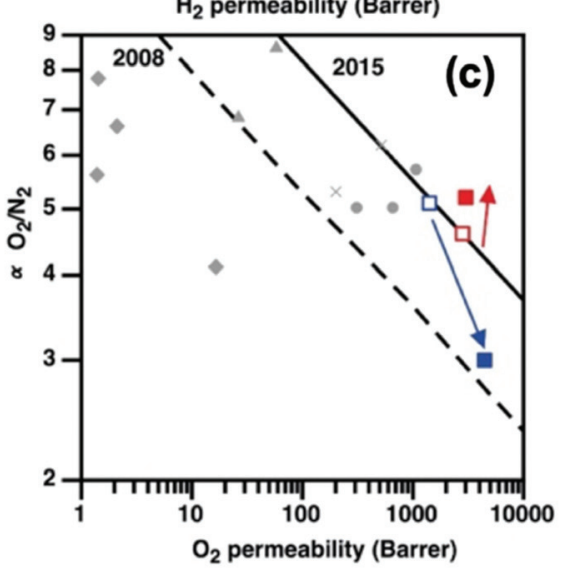

Fig. 6 The initial impact of PAF-1 incorporation on (a) $\mathrm{H}_{2} / \mathrm{N}_{2}$, (b) $\mathrm{H}_{2} /$ $\mathrm{CH}_{4}$, and (c) $\mathrm{O}_{2} / \mathrm{N}_{2}$ separation for as-cast PIM-EA(Me $\mathrm{Me}_{2}$-TB $(\square)$, PIM-EA $\left(\mathrm{Me}_{2}\right)$-TB/PAF-1 ( $\square$ ), PIM-EA $\left(\mathrm{H}_{2}\right)$-TB $(\square)$, and PIM-EA( $\left.\mathrm{H}_{2}\right)$-TB/PAF-1 ( $\square$ ) films. Also shown for comparison are data for current state-of-the-art polymers such as triptycene PIMs $(\Lambda),{ }^{40}$ triptycene polyimides $(X),{ }^{41}$ commercial polymers $(\$),{ }^{42}$ and other PIMs $(0){ }^{43}$

(Fig. S21†). This contrasting effect of PAF-1 on gas permeation in PIMs with similar chemical structures was attributed to the difference in gas diffusion modes. The $60 \%$ increase in PIM-EA(Me $\left.\mathrm{M}_{2}\right)$-TB $d$-spacing due to blending with PAF-1 was sufficient to support a Knudsen diffusion mechanism for $\mathrm{H}_{2}$ but not for larger gases like $\mathrm{N}_{2}$ and $\mathrm{CH}_{4} \cdot{ }^{45}$ This enhanced $\mathrm{H}_{2}$ separation from $\mathrm{CH}_{4}$ and $\mathrm{N}_{2}$, leading to $\mathrm{H}_{2} / \mathrm{CH}_{4}$ separation performances. The compatibility of PIM-EA(Me $\left.\mathrm{Me}_{2}\right) \mathrm{TB} / \mathrm{PAF}-1$ resulted in selective aging that benefitted the transport of $\mathrm{He}$ and $\mathrm{H}_{2}$ gas molecules, similar to other PIM/PAF membranes, where some physical aging drivers remain untethered to PAF- $1 .{ }^{18}$ The excellent $\mathrm{H}_{2}$ permeabilities and $\mathrm{H}_{2} / \mathrm{CH}_{4}$ selectivities of aged PIM-EA(Me $\mathrm{Me}_{2}$-TB/PAF-1 at realistic operating conditions (Table S10, Fig. S26, ESI $\dagger$ ) are ideal for exploiting these mixed matrix membranes for recovering $\mathrm{H}_{2}$ from the off-gas of hydrocracker refineries in high temperature and pressure conditions. ${ }^{46}$

\section{Conclusions}

In summary, through a very simple change in the structure of a PIM, we elucidated the mechanism leading to controlling both plasticisation and physical aging in ultrapermeable nanocomposites. The absence of pendant methyl groups resulted in PIM chains that aggregated and prevented fine intercalation with PAF-1 nanoparticles; minimizing the benefits of PAF-1 towards enhancing membrane separation and the effects of aging and rigid polymer chains. Hence, polymer additive compatibility could be manipulated to direct specific molecularscale interactions between the bulk matrix and the additive at precise locations of the polymer chains; allowing facile design of mixed matrix membranes that age differently. In addition, these ultrapermeable composites demonstrated some form of chain rigidification, even at high pressures and temperatures. $\mathrm{PIM} / \mathrm{PAF}$ composites have potential for membrane gas separations involving important gases for the global economy, in addition to the described performance of separating $\mathrm{H}_{2}$ from natural gas. These include $\mathrm{He}$ mining from natural gases, $\mathrm{O}_{2}$ or $\mathrm{N}_{2}$ enrichment of air and $\mathrm{H}_{2}$ separation from ammonia purge gases.

\section{Conflicts of interest}

There are no conflicts to declare.

\section{Acknowledgements}

We thank Dr Adrian Hawley at the Australian Synchrotron for setting up the SAXS/WAXS beamline, and Dr Roger Mulder at CSIRO for performing solid state NMR experiments. CHL acknowledges funding support from the University of Edinburgh Chancellor's Fellowship.

\section{References}

1 D. S. Sholl and R. P. Lively, Nature, 2016, 532, 435-437.

2 D.-Y. Koh, B. A. McCool, H. W. Deckman and R. P. Lively, Science, 2016, 353, 804-807.

3 D. F. Sanders, Z. P. Smith, R. Guo, L. M. Robeson, J. E. McGrath, D. R. Paul and B. D. Freeman, Polymer, 2013, 54, 4729-4761. 
4 R. W. Baker and B. T. Low, Macromolecules, 2014, 47, 69997013.

5 P. Marchetti, M. F. Jimenez Solomon, G. Szekely and A. G. Livingston, Chem. Rev., 2014, 114, 10735-10806.

6 H. Wang, T. S. Chung and D. R. Paul, J. Membr. Sci., 2014, 458, 27-35.

7 S. Kim and Y. M. Lee, Prog. Polym. Sci., 2015, 43, 1-32.

8 R. Swaidan, B. Ghanem, E. Litwiller and I. Pinnau, Macromolecules, 2015, 48, 6553-6561.

9 N. R. Horn and D. R. Paul, Macromolecules, 2012, 45, 28202834.

10 M. Wessling, S. Schoeman, T. van der Boomgaard and C. A. Smolders, Gas Sep. Purif., 1991, 5, 222-228.

11 B. W. Rowe, B. D. Freeman and D. R. Paul, Polymer, 2009, 50, 5565-5575.

12 S. Japip, K.-S. Liao and T.-S. Chung, Adv. Mater., 2017, 29, 1603833.

13 C. H. Lau, P. T. Nguyen, M. R. Hill, A. W. Thornton, K. Konstas, C. M. Doherty, R. J. Mulder, L. Bourgeois, A. C. Y. Liu, D. J. Sprouster, J. P. Sullivan, T. J. Bastow, A. J. Hill, D. L. Gin and R. D. Noble, Angew. Chem., Int. Ed., 2014, 53, 5322-5326.

14 Z. Kang, Y. Peng, Y. Qian, D. Yuan, M. A. Addicoat, T. Heine, Z. Hu, L. Tee, Z. Guo and D. Zhao, Chem. Mater., 2016, 28, 1277-1285.

15 M. Kitchin, J. Teo, K. Konstas, C. H. Lau, C. J. Sumby, A. W. Thornton, C. J. Doonan and M. R. Hill, J. Mater. Chem. A, 2015, 3, 15241-15247.

16 C. H. Lau, X. Mulet, K. Konstas, C. M. Doherty, M.-A. Sani, F. Separovic, M. R. Hill and C. D. Wood, Angew. Chem., Int. Ed., 2016, 55, 1998-2001.

17 T. Mitra, R. S. Bhavsar, D. J. Adams, P. M. Budd and A. I. Cooper, Chem. Commun., 2016, 52, 5581-5584.

18 C. H. Lau, K. Konstas, A. W. Thornton, A. C. Y. Liu, S. Mudie, D. F. Kennedy, S. C. Howard, A. J. Hill and M. R. Hill, Angew. Chem., Int. Ed., 2015, 54, 2669-2673.

19 S. J. D. Smith, K. Konstas, C. H. Lau, Y. M. Gozukara, C. D. Easton, R. J. Mulder, B. P. Ladewig and M. R. Hill, Cryst. Growth Des., 2017, 17, 4384-4392.

20 J. E. Bachman, Z. P. Smith, T. Li, T. Xu and J. R. Long, Nat. Mater., 2016, 15, 845-849.

21 T. Ben, H. Ren, S. Ma, D. Cao, J. Lan, X. Jing, W. Wang, J. Xu, F. Deng, J. M. Simmons, S. Qiu and G. Zhu, Angew. Chem., 2009, 121, 9621-9624.

22 M. Carta, R. Malpass-Evans, M. Croad, Y. Rogan, J. C. Jansen, P. Bernardo, F. Bazzarelli and N. B. McKeown, Science, 2013, 339, 303-307.

23 P. Bernardo, V. Scorzafave, G. Clarizia, E. Tocci, J. C. Jansen, A. Borgogno, R. Malpass-Evans, N. B. McKeown, M. Carta and F. Tasselli, J. Membr. Sci., 2019, 569, 17-31.
24 A. J. Hill, S. J. Pas, T. J. Bastow, M. I. Burgar, K. Nagai, L. G. Toy and B. D. Freeman, J. Membr. Sci., 2004, 243, 37-44.

25 C. L. Staiger, S. J. Pas, A. J. Hill and C. J. Cornelius, Chem. Mater., 2008, 20, 2606-2608.

26 C. H. Lau, K. Konstas, C. M. Doherty, S. Kanehashi, B. Ozcelik, S. E. Kentish, A. J. Hill and M. R. Hill, Chem. Mater., 2015, 27, 4756-4762.

27 M. T. Pastor, A. Giménez-Giner and E. Pérez-Payá, ChemBioChem, 2005, 6, 1753-1756.

28 R. E. Koeppe, J. Hatchett, A. R. Jude, L. L. Providence, O. S. Andersen and D. V. Greathouse, Biochemistry, 2000, 39, 2235-2242.

29 Y. Umezawa, S. Tsuboyama, H. Takahashi, J. Uzawa and M. Nishio, Tetrahedron, 1999, 55, 10047-10056.

30 S. Tsuzuki, K. Honda, T. Uchimaru, M. Mikami and K. Tanabe, J. Am. Chem. Soc., 2000, 122, 3746-3753.

31 A. B. Foster, M. Tamaddondar, J. M. Luque-Alled, W. J. Harrison, Z. Li, P. Gorgojo and P. M. Budd, Macromolecules, 2020, 53, 569-583.

32 C. R. Mason, L. Maynard-Atem, K. W. J. Heard, B. Satilmis, P. M. Budd, K. Friess, M. Lanč, P. Bernardo, G. Clarizia and J. C. Jansen, Macromolecules, 2014, 47, 1021-1029.

33 Z.-X. Wang, C.-H. Lau, N.-Q. Zhang, Y.-P. Bai and L. Shao, J. Mater. Chem. A, 2015, 3, 2650-2657.

34 R. J. Hill, Phys. Rev. Lett., 2006, 96, 216001.

35 R. R. Tiwari, J. Jin, B. D. Freeman and D. R. Paul, J. Membr. Sci., 2017, 537, 362-371.

36 O. Vopička, M. G. De Angelis, N. Du, N. Li, M. D. Guiver and G. C. Sarti, J. Membr. Sci., 2014, 459, 264-276.

37 D. R. Paul, in Encyclopedia of Membranes, ed. E. Drioli and L. Giorno, Springer Berlin Heidelberg, Berlin, Heidelberg, 2016, pp. 1-2, DOI: 10.1007/978-3-642-40872-4_662-3.

38 Y. Xiao, B. T. Low, S. S. Hosseini, T. S. Chung and D. R. Paul, Prog. Polym. Sci., 2009, 34, 561-580.

39 T.-S. Chung, L. Y. Jiang, Y. Li and S. Kulprathipanja, Prog. Polym. Sci., 2007, 32, 483-507.

40 M. Carta, M. Croad, R. Malpass-Evans, J. C. Jansen, P. Bernardo, G. Clarizia, K. Friess, M. Lanč and N. B. McKeown, Adv. Mater., 2014, 26, 3526-3531.

41 B. S. Ghanem, R. Swaidan, E. Litwiller and I. Pinnau, Adv. Mater., 2014, 26, 3688-3692.

42 L. M. Robeson, W. F. Burgoyne, M. Langsam, A. C. Savoca and C. F. Tien, Polymer, 1994, 35, 4970-4978.

43 P. M. Budd, K. J. Msayib, C. E. Tattershall, B. S. Ghanem, K. J. Reynolds, N. B. McKeown and D. Fritsch, J. Membr. Sci., 2005, 251, 263-269.

44 R. Swaidan, B. Ghanem and I. Pinnau, ACS Macro Lett., 2015, 4, 947-951.

45 A. W. Thornton, T. Hilder, A. J. Hill and J. M. Hill, J. Membr. Sci., 2009, 336, 101-108.

46 R. W. Baker, Ind. Eng. Chem. Res., 2002, 41, 1393-1411. 